\title{
Foveal structure in nanophthalmos and visual acuity
}

\author{
Hideaki Okumichi (i) - Katsumasa Itakura (D) Yuki Yuasa (id) Atsuhiko Fukuto • \\ Yoshiaki Kiuchi $\mathbb{B}$
}

Received: 18 June 2020/Accepted: 29 October 2020/Published online: 13 November 2020

(C) The Author(s) 2020

\begin{abstract}
Purpose To evaluate the fovea in nanophthalmic eyes using spectral domain optical coherence tomography (SD-OCT) and OCT angiography (OCTA), and to investigate the relationship between the macular microstructure and visual acuity.

Methods This is a retrospective case series of five nanophthalmic patients. The foveal avascular zone (FAZ) area was measured in superficial and deep vascular layers with OCTA. The thickness of the inner retinal layer (IRL) was measured with SD-OCT. The ratio of the foveal and parafoveal IRL thickness (fIRL/ pIRL ratio) was calculated. The relationship between these parameters and visual acuity was then investigated.

Results Eight eyes were identified as nanophthalmic with a mean axial length of $17.19 \pm 1.44 \mathrm{~mm}$ (range: 15.71 to $19.88 \mathrm{~mm}$ ). The mean best-corrected visual acuity (BCVA) in the logarithm of the minimum angle of resolution (logMAR) was $0.12 \pm 0.18$ (range: -0.18 to 0.40 ). OCTA showed that FAZs were either absent or undeveloped in the superficial and deep capillary plexuses. Two patients did not show any
\end{abstract}

H. Okumichi $(\bowtie) \cdot$ K. Itakura · Y. Yuasa .

A. Fukuto · Y. Kiuchi

Department of Ophthalmology and Visual Science,

Hiroshima University Graduate School of Biomedical and

Health Sciences, 1-2-3 Kasumi, Minamiku,

Hiroshima 7348551, Japan

e-mail: okumic@hiroshima-u.ac.jp visual impairments despite small FAZ and a shallow foveal depression. Although the BCVA was significantly correlated with the deep FAZ size, it did not correlate with the superficial FAZ size, axial length, or fIRL/pIRL ratio. However, the refractive error, axial length, and deep FAZ size were all significantly correlated with the fIRL/pIRL ratio.

Conclusions The FAZs were commonly found to be small in the superficial and deep capillary plexuses. Although the deep FAZ size correlated with visual acuity, it is unclear whether the retinal microstructure and the FAZ size are responsible for the visual impairments observed in the same individuals.

Keywords Nanophthalmos · Visual acuity · OCT angiography $\cdot$ Foveal avascular zone

\section{Introduction}

Nanophthalmos is a rare congenital eye disorder that is characterized by an axial length under $20 \mathrm{~mm}$. This condition causes a variety of morphological and functional anomalies, such as hyperopia, microcornea, shallow anterior chamber, angle-closure glaucoma, and thickened sclera $[1,2]$. This condition is also associated with foveal hypoplasia and an absent foveal avascular zone (FAZ) [3]. 
Although previous reports have analyzed retinal and choroidal changes occurring in nanophthalmic eyes, using either optical coherence tomography (OCT) [4-6] or fluorescein angiography [3], it remains unclear whether a causal relationship exists between the abnormal retinal vascular structure and a reduction in visual acuity. OCT angiography (OCTA) has been validated as a novel and non-invasive method to measure blood flow within the fundus in two different vascular layers (superficial and deep vascular plexuses) without the need for a fluorescein dye injection $[7,8]$.

The purpose of this report is to describe the foveal structure and vasculature of nanophthalmic eyes using OCTA and spectral domain (SD)-OCT and to investigate the relationship between these measures and visual acuity.

\section{Patients and methods}

This is a retrospective case series study of five consecutive nanophthalmic patients examined in the glaucoma department of Hiroshima University Hospital, Hiroshima, Japan, from June 1, 2016, to January 31, 2018. All procedures were performed in accordance with the Declaration of Helsinki and were approved by the Ethics Committee of Hiroshima University Hospital (E-1709). Written informed consent was obtained from all patients.

Five participants underwent comprehensive ophthalmic examinations, which included slit-lamp biomicroscopy, gonioscopy, fundus photography, SD-OCT, and OCTA. Measurements of axial length, best-corrected visual acuity (BCVA), and refractive correction were also obtained. A diagnosis of nanophthalmos was given in cases where the axial length was under $20 \mathrm{~mm}$. OCTA and SD-OCT were performed with an RTVue XR Avanti (Optovue Inc., Fremont, CA, USA) imaging system using a $3.00 \times 3.00 \mathrm{~mm}$ resolution to evaluate both the superficial and deep capillary plexus layers. Two eyes were excluded from further analyses: one had proliferative vitreoretinopathy (Case 4, OS) and the other did not meet the axial length $(20.31 \mathrm{~mm})$ criterion for nanophthalmos (Case 5, OD).

In order to evaluate the extent of foveal development, measurements of FAZ size and thickness were obtained for both the fovea and parafovea. The foveal to parafoveal inner retinal layer ratio (fIRL/pIRL ratio) was subsequently calculated as previously described [9]. During early foveal development, retinal axons and blood vessels are displaced outward to form the invagination of the fovea, thus producing the FAZ [10]. Therefore, an increased fIRL/pIRL ratio indicates an immature and underdeveloped fovea [11]. From the OCTA images, the FAZ area was measured manually using Adobe Photoshop (version CC 2017; Adobe Systems Inc., San Jose, CA, USA). The length or area size measured in OCT/OCTA images is needed to be corrected by axial length. The coefficient by axial length $(\mathrm{CoAx})$ was calculated as $\mathrm{CoAx}=3.382$ [0.01306 $(\mathrm{Ax}-1.82)]$. The measured area size was corrected by the factor $\mathrm{CoAx}^{2}$ [12]. The IRL thickness was also manually measured from the SD-OCT images for both fovea and parafovea $(1000 \mu \mathrm{m}$ nasal from the foveal center) sites. Finally, the fIRL/pIRL ratio was subsequently calculated.

Statistical analyses were performed with JMP ${ }^{\circledR}$ Pro 14.0.0 (SAS Institute Inc., Cary, NC). Correlations between the corrected superficial and deep FAZ sizes, BCVA in the logarithm of the minimum angle of resolution ( $\log M A R)$, fIRL/pIRL ratios, refractive errors, and axial lengths were investigated using Spearman's rank correlation coefficient. Statistical significance was set at $P<0.05$.

\section{Results}

Eight eyes were diagnosed as nanophthalmic. The mean age of the participants was $49 \pm 13$ years (range: $37-70$ years), the mean axial length was $17.19 \pm 1.44 \mathrm{~mm}$ (range: $15.71-19.88 \mathrm{~mm}$ ), and the mean BCVA in logMAR was $0.12 \pm 0.18$ (range: 0.18-0.40) (Table 1). Gonioscopy examinations showed shallow anterior chambers and narrow angles (Shaffer 2, Sheie 4) in all patients.

Using OCTA, it was ascertained that the FAZ was either absent or rudimentary in both the superficial and deep vascular layers (Table 1) (Fig. 1). The FAZ was completely absent in three eyes (Cases 3 and 4) and was small or underdeveloped in the superficial layer of four eyes (Cases 1,2, and 5). The corrected size of observable FAZs varied from 0.028 to $0.106 \mathrm{~mm}^{2}$ in superficial layers and from 0.032 to $0.216 \mathrm{~mm}^{2}$ in deep layers (Table 2). Five eyes (Cases 1, 3, and 4) were found to have shallow foveal pit based on OCT 
Table 1 OCTA measurements in five nanophthalmos cases

\begin{tabular}{|c|c|c|c|c|c|c|c|c|c|c|c|}
\hline Case & $\begin{array}{l}\text { Age } \\
\text { (years) }\end{array}$ & Gender & $\begin{array}{l}\text { OD/ } \\
\text { OS }\end{array}$ & $\begin{array}{l}\text { BCVA } \\
(\log M A R)\end{array}$ & $\begin{array}{l}\text { Refraction } \\
\text { (D) }\end{array}$ & $\begin{array}{l}\text { Axial } \\
\text { length } \\
(\mathrm{mm})\end{array}$ & $\begin{array}{l}\text { Superficial } \\
\text { FAZ area } \\
\left(\mathrm{mm}^{2}\right)\end{array}$ & $\begin{array}{l}\text { Deep FAZ } \\
\text { area } \\
\left(\mathrm{mm}^{2}\right)\end{array}$ & $\begin{array}{l}\text { fIRL } \\
\text { thickness } \\
(\mu \mathrm{m})\end{array}$ & $\begin{array}{l}\text { pIRL } \\
\text { thickness } \\
(\mu \mathrm{m})\end{array}$ & $\begin{array}{l}\text { fIRL/ } \\
\text { pIRL } \\
\text { ratio }\end{array}$ \\
\hline \multirow[t]{2}{*}{1} & \multirow[t]{2}{*}{70} & \multirow[t]{2}{*}{ Female } & OD & 0.40 & +8.00 & 16.27 & 0.068 & 0.147 & 78.13 & 208.33 & 0.38 \\
\hline & & & OS & 0.30 & +8.00 & 16.25 & 0.215 & 0.413 & 33.85 & 187.50 & 0.18 \\
\hline \multirow[t]{2}{*}{2} & \multirow[t]{2}{*}{48} & \multirow[t]{2}{*}{ Female } & OD & 0.15 & +9.75 & 18.06 & 0.206 & 0.259 & 28.65 & 210.94 & 0.14 \\
\hline & & & OS & 0.15 & +9.75 & 18.01 & Defect & 0.423 & 20.83 & 169.27 & 0.12 \\
\hline \multirow[t]{2}{*}{3} & \multirow[t]{2}{*}{45} & \multirow[t]{2}{*}{ Male } & OD & 0 & +16.00 & 15.71 & Defect & Defect & 177.08 & 242.19 & 0.73 \\
\hline & & & OS & 0 & +16.00 & 15.83 & Defect & Defect & 234.38 & 213.54 & 1.10 \\
\hline 4 & 43 & Female & OD & -0.18 & +10.25 & 17.48 & Defect & Defect & 226.56 & 234.38 & 0.97 \\
\hline 5 & 37 & Female & OS & 0.10 & +3.50 & 19.88 & 0.123 & 0.050 & 7.81 & 138.02 & 0.06 \\
\hline
\end{tabular}

OCTA optical coherence tomography angiography, BCVA best-corrected visual acuity, $\log M A R$ logarithm of minimum angle of resolution, $D$ diopter, $F A Z$ foveal avascular zone, $f I R L$ foveal inner retinal layer, $p I R L$ parafoveal inner retinal layer

findings. Three eyes (Cases 3 and 4) had normal visual acuity despite having FAZ abnormalities in either the superficial or deep capillary plexuses and an abnormal foveal depression.

Correlation analyses revealed a significant relationship between the BCVA in logMAR and the size of the deep FAZ ( $\rho=0.79, P=0.0196)$. However, the BCVA did not correlate with the superficial FAZ area, the fIRL/pIRL ratio, refractive error, or axial length (Fig. 2). Although the size of both the superficial and deep FAZ was not correlated with the axial length, a significant correlation was found between the deep FAZ size and the fIRL/pIRL ratio $(\rho=-0.71$, $P=0.0496$ ). The fIRL/pIRL ratio was also significantly correlated with the refractive error $(\rho=0.74$, $P=0.0378)$ and with the axial length $(\rho=-0.76$, $P=0.0280)$, but not with the superficial FAZ size (Fig. 3). The refractive error was not significantly correlated with either the superficial FAZ or deep FAZ size, nor with the axial length. The superficial and deep FAZ sizes were not significantly correlated with one another (Table 3).

\section{Discussion}

In the present study, we confirmed the structural characteristics of the nanophthalmic macula and quantified the FAZ size and the IRL thickness for both the fovea and parafovea using OCTA and SDOCT. Moreover, we found a significant correlation between the BCVA and the deep FAZ size. In addition, the fIRL/pIRL ratio, an indicator of hypoplasia, was significantly correlated with the refractive error, axial length, and deep FAZ size. However, the fIRL/pIRL ratio was not significantly correlated with either the BCVA or superficial FAZ size.

The measured FAZ sizes were smaller than that observed in normal adult eyes $\left(0.05-1.05 \mathrm{~mm}^{2}\right.$ ) without distinction between vascular layers [13]. Furthermore, the average fIRL/pIRL ratio was $0.46 \pm 0.41$ with a range from 0.06 to 1.10 , which was significantly greater than the average measure for normal adult eyes $(0.05$, range: $0.00-0.20)$ [11]. This result indicates that the fIRL thickness is larger in nanophthalmic eyes, which might in turn cause an undeveloped FAZ.

Foveal hypoplasia can be found in patients with one of several other eye disorders such as albinism, PAX6 gene mutations with aniridia, isolated foveal hypoplasia, achromatopsia [14], retinopathy of prematurity [15], and Stickler syndrome [9]. Studies investigating these disorders suggested that OCT was the ideal method to establish the structural grading system of foveal hypoplasia [14]. Furthermore, Matsushita et al. investigated patients with foveal hypoplasia due to Stickler syndrome using OCT and OCTA, in addition to calculating the fIRL/pIRL ratio [9]. Their results appeared to be similar to those found in the present study in terms of the relatively low-grade foveal hypoplasia (mostly Grade 1 or 2), the persistence of the IRL, and the preserved visual acuity in some patients. Therefore, the presence of foveal morphological anomalies is not always predictive of visual acuity impairments. 
Fig. 1 Comparison of the cross-sectional optical coherence tomography (OCT) images (left) and optical coherence tomography angiography (OCTA) images of the superficial (middle) and deep (right) capillary plexuses from all eight eyes. The thickness of the foveal inner retinal layer (fIRL) and parafoveal inner retinal layer (pIRL), in addition to the area of the foveal avascular zone (FAZ), were all measured manually. Subsequently, fIRL/pIRL ratio was calculated and the size of FAZ area was corrected by axial length

\section{OCT}
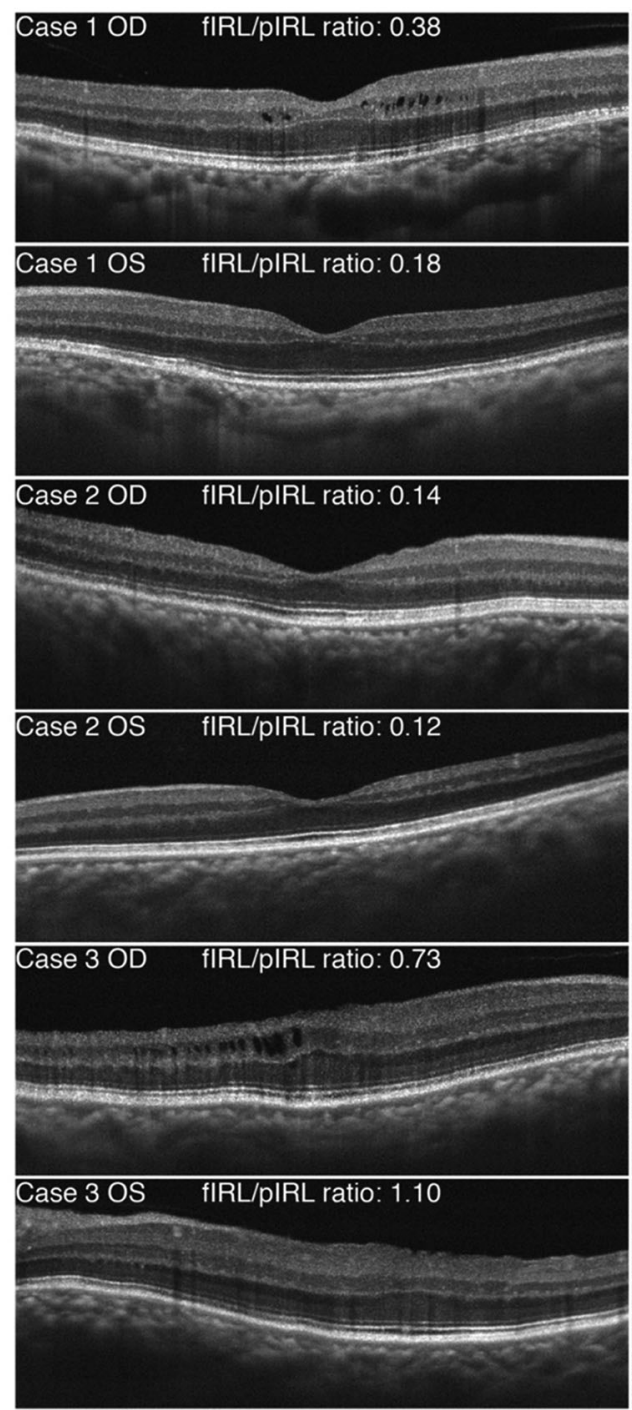

Case 4 OD fIRL/pIRL ratio: 0.97

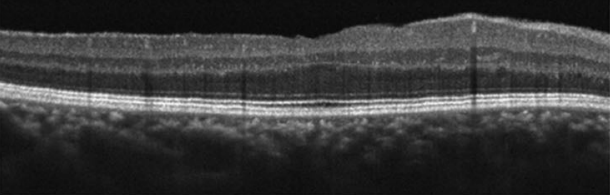

Case 5 OS fIRL/pIRL ratio: 0.06

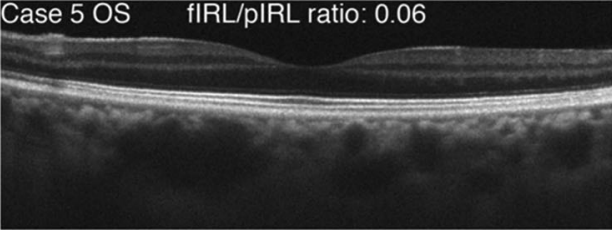

\section{OCTA \\ Superficial \\ Deep}
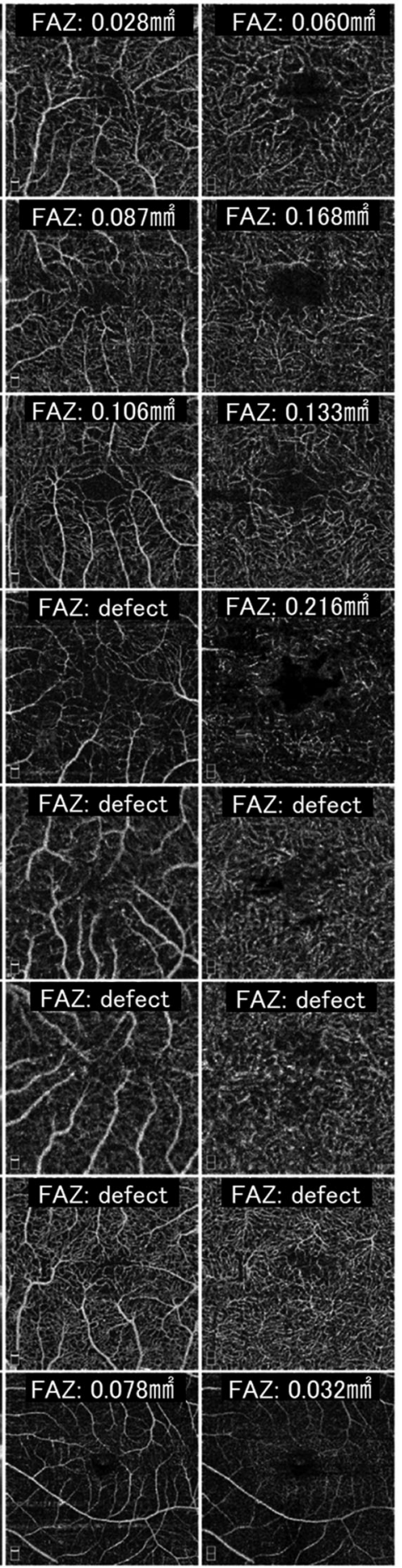
Table 2 Correction of FAZ area size

\begin{tabular}{|c|c|c|c|c|c|}
\hline Case & $\mathrm{OD} / \mathrm{OS}$ & Axial length $(\mathrm{mm})$ & CoAx & Corrected superficial FAZ area $\left(\mathrm{mm}^{2}\right)$ & Corrected deep FAZ area $\left(\mathrm{mm}^{2}\right)$ \\
\hline \multirow[t]{2}{*}{1} & OD & 16.27 & 0.64 & 0.028 & 0.060 \\
\hline & OS & 16.25 & 0.64 & 0.087 & 0.168 \\
\hline \multirow[t]{2}{*}{2} & OD & 18.06 & 0.72 & 0.106 & 0.133 \\
\hline & OS & 18.01 & 0.72 & 0 & 0.216 \\
\hline \multirow[t]{2}{*}{3} & OD & 15.71 & 0.61 & 0 & 0 \\
\hline & OS & 15.83 & 0.62 & 0 & 0 \\
\hline 4 & OD & 17.48 & 0.69 & 0 & 0 \\
\hline 5 & OS & 19.88 & 0.80 & 0.078 & 0.032 \\
\hline
\end{tabular}

$F A Z$ foveal avascular, $\operatorname{CoAX}$ coefficient by axial length

a

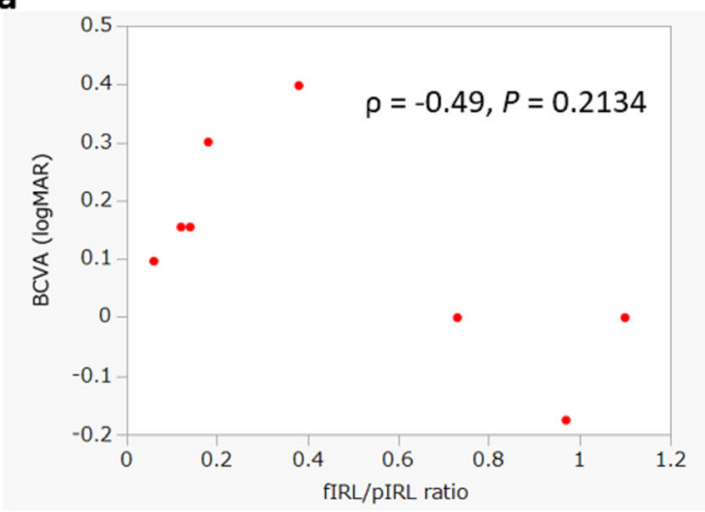

C

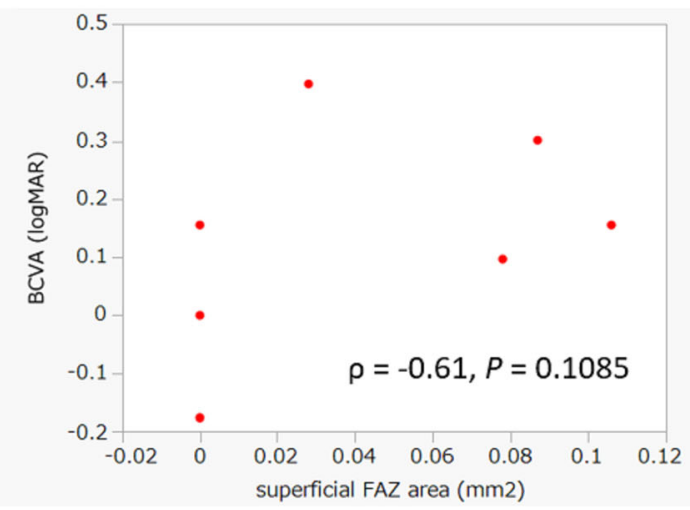

Fig. 2 Correlations between the visual acuity ( $\log M A R)$, the fIRL/pIRL thickness ratio, the axial length, and the size of superficial and deep FAZ. Correlations were computed using Spearman's rank correlation coefficient. The correlation between a the visual acuity and the fIRL/pIRL ratio, between

The fovea is considered a specialized and critical region of the retina because it contains the highest cone photoreceptor density, which enables high visual b

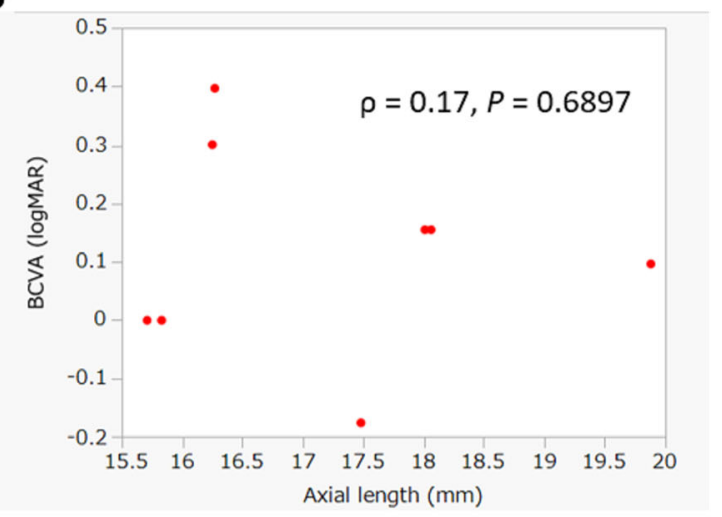

d

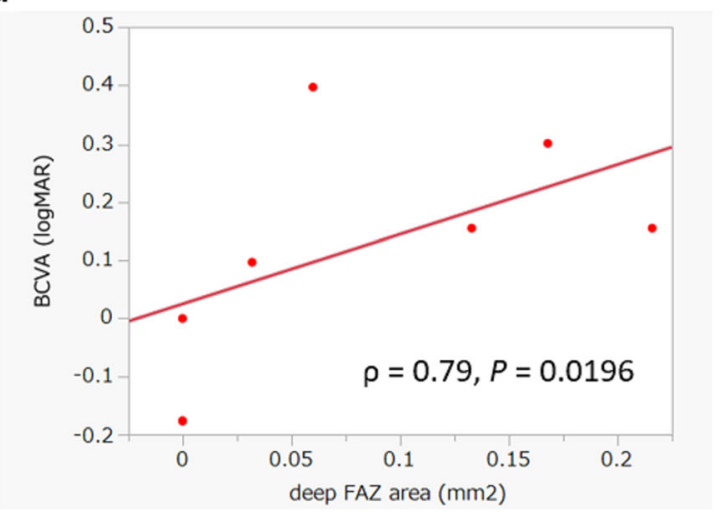

b the visual acuity and the axial length and between $\mathbf{c}$ the visual acuity and the size of superficial FAZ were not significant, whereas the correlation between $\mathbf{d}$ the visual acuity and the size of deep FAZ ( $\rho=0.79, P=0.0196)$ was significant

acuity and color vision [16]. The development of the foveal pit begins at fetal week 25 and the excavation is accomplished between months 15 to 45 after birth 
a

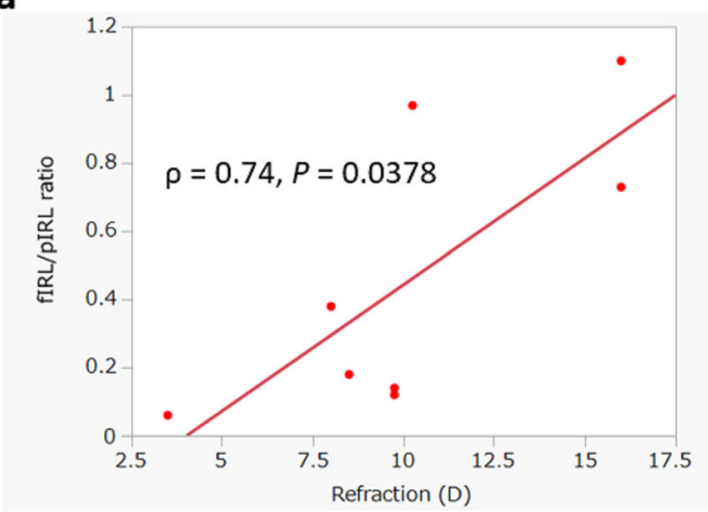

c

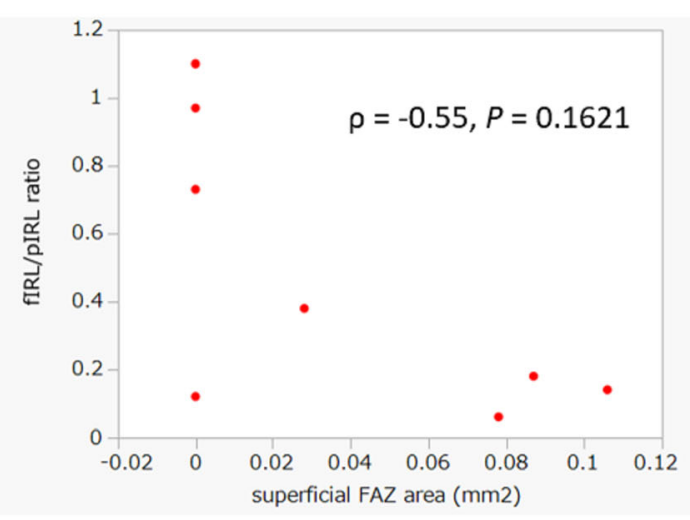

Fig. 3 Correlations between the fIRL/pIRL ratio, the refractive error, the axial length, and the size of superficial and deep FAZ. Correlations were computed using Spearman's rank correlation coefficient. The correlation between a the fIRL/pIRL ratio and the refractive error ( $\rho=0.74, P=0.0378$ ), between $\mathbf{b}$ the fIRL/

$[10,17]$. During the foveal developmental process, the foveal pit is created by bidirectional movements of the retinal neuronal cells. The inner retinal cells are relocated outside the foveal pit, whereas cone photoreceptor cells move inward to increase their concentration within the foveal pit [18]. However, those inner and outer retinal layer changes occur separately at different time points. Molecular analysis of the macular region indicates that at fetal week eight, axon guidance molecules act initially to repel axons and subsequently blood vessels to form FAZ [19, 20], which is then followed by foveal pit formation beginning at fetal week 25 [21]. In contrast, outer retinal development, such as cone elongation and packing, mainly occurs postnatally [10]. In the foveal outer segment, the cone density continues to rise until a threefold increase is reached approximately b

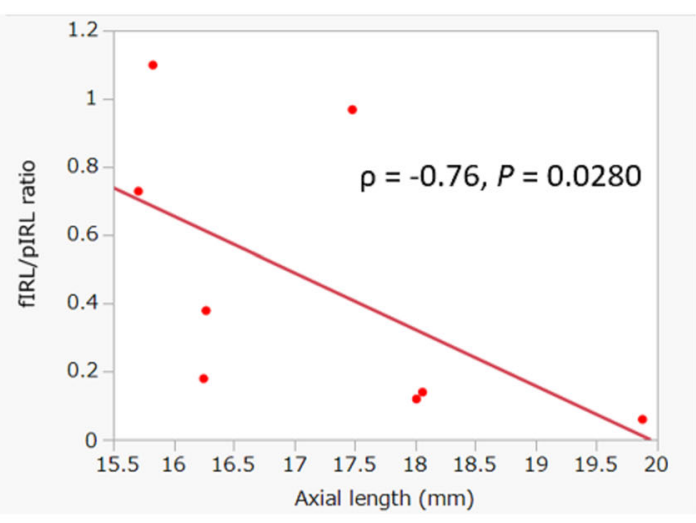

d

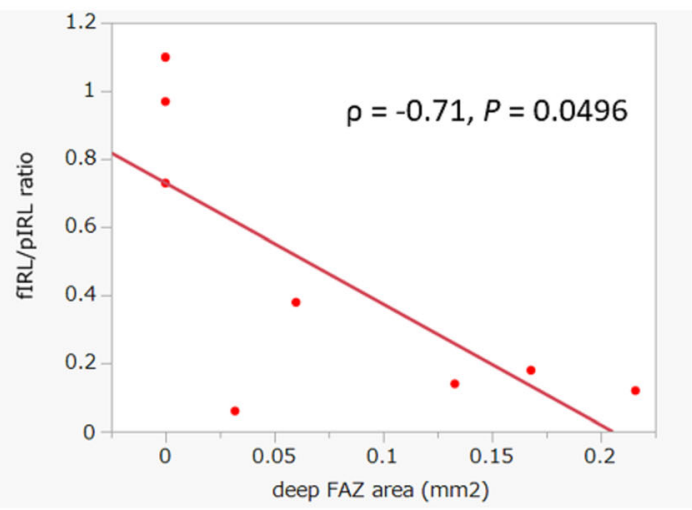

pIRL ratio and the axial length $(\rho=-0.76, P=0.0280)$ and between $\mathbf{d}$ the fIRL/pIRL ratio and the size of deep FAZ ( $\rho=-0.71, P=0.0496$ ) were significant, whereas the correlation between $\mathbf{c}$ the fIRL/pIRL ratio and the size of superficial FAZ was not significant

3.8 years after birth; however, the cause of this increase is not yet known [22].

Furthermore, the relationship between abnormal FAZs (either in superficial or deep capillary plexuses) and visual acuity is not clear. Interestingly, eyes with smaller FAZs in deep layers had better visual acuity despite also having higher fIRL/pIRL ratios compared with other eyes. Previous reports showed that diminished macular vasculature was associated with structural and functional damage in glaucoma [23] and that the vessel density in superficial layers was greater than in deep layers [7]. These findings contradict the present results and do not explain why smaller FAZs in the deep retinal layers are associated with better visual acuity. Therefore, it remains unclear whether morphological abnormalities arising from nanophthalmos lead to visual dysfunctions. In subjects with nanophthalmos, the eyeball cannot fully develop during the 
Table 3 Spearman's rank correlation coefficient

\begin{tabular}{|c|c|c|}
\hline & Coefficient $(\rho)$ & $P$ \\
\hline \multicolumn{3}{|l|}{ BCVA vs. } \\
\hline Superficial FAZ & 0.61 & 0.1085 \\
\hline Deep FAZ & 0.79 & $0.0196 *$ \\
\hline fIRL/pIRL ratio & -0.49 & 0.2134 \\
\hline Refraction & -0.68 & 0.0619 \\
\hline Axial length & 0.17 & 0.6897 \\
\hline \multicolumn{3}{|c|}{ Superficial FAZ vs. } \\
\hline Deep FAZ & 0.49 & 0.2135 \\
\hline fIRL/pIRL ratio & -0.55 & 0.1621 \\
\hline Refraction & -0.65 & 0.0821 \\
\hline Axial length & 0.46 & 0.2554 \\
\hline \multicolumn{3}{|l|}{ Deep FAZ vs. } \\
\hline fIRL/pIRL ratio & -0.71 & $0.0496 *$ \\
\hline Refraction & -0.54 & 0.1641 \\
\hline Axial length & 0.41 & 0.3069 \\
\hline \multicolumn{3}{|c|}{ fIRL/pIRL ratio vs. } \\
\hline Refraction & 0.74 & $0.0378 *$ \\
\hline Axial length & -0.76 & $0.0280 *$ \\
\hline \multicolumn{3}{|l|}{ Refraction vs. } \\
\hline Axial length & -0.63 & 0.0965 \\
\hline
\end{tabular}

$B C V A$ best-corrected visual acuity, $F A Z$ foveal avascular zone, $f I R L$ foveal inner retinal layer, pIRL parafoveal inner retinal layer

$* P<0.05$

embryonic stage, resulting in macular hypoplasia [24]. Since visual acuity reaches maturity long after birth, it is possible that appropriate therapeutic approaches can help prevent visual impairments in nanophthalmos cases while the outer segment of the retina is not yet fully developed. Results from the study of other conditions that also produce foveal hypoplasia such as albinism [25], retinopathy of prematurity [15], and Stickler syndrome [9] also support the present findings indicating that anatomical abnormalities do not always correlate with visual acuity.

Some limitations of the present study should be addressed. First, the sample size was notably small. Accumulating additional OCTA and OCT data might help to determine if a significant association exists between the foveal structure, vessel plexus, and visual outcomes. Second, the automated measurement of the FAZ was not without issues as in some cases it appeared to be inaccurate. In particular, for undeveloped FAZ cases, we found that it tended to overestimated linings, which then require manual adjustments with Photoshop. In addition, there is the possibility of segmentation errors. The segmentation of the superficial capillary plexus using OCTA images is determined as a slab starting $3 \mu \mathrm{m}$ below the internal limiting membrane and ending $15 \mu \mathrm{m}$ under the inner plexiform layer [26]. Since the IRL thickness differed for each participant, this may have led to imprecise FAZ measurements.

\section{Conclusions}

We report here OCTA and SD-OCT features for five nanophthalmos cases. We identified abnormal FAZs in the deep and superficial retinal layers, in addition to underdeveloped retinal microstructures. However, our findings did not show a clear relationship between these structural changes and visual function, even though the deep FAZ size was correlated with the BCVA. Further studies with larger sample sizes will be necessary to develop a better understanding of how both variables are linked.

Acknowledgements We thank Dr. Patrice Voss from Edanz Group (www.edanzediting.com/) for editing a draft of this manuscript.

Author contributions Yoshiaki Kiuchi conceived of an idea of this study. All authors contributed to the study design. OCT/ OCTA measurements were performed by Atsuhiko Fukuto. Data collection was performed by Katsumasa Itakura and Yuki Yuasa. Analysis was performed by Hideaki Okumichi and Yuki Yuasa. The first draft of the manuscript was written by Katsumasa Itakura, and all authors commented on the previous versions of the manuscript. All authors read and approved the final manuscript.

Funding No funding has been declared.

\section{Compliance with ethical standards}

Conflict of interest The authors declare that they have no conflict of interest.

Ethical approval All procedures performed in studies involving human participants were in accordance with the ethical standards of the Institutional Review Board of the Hiroshima University Hospital, Hiroshima, Japan and with the 1964 Helsinki Declaration and its later amendments or comparable ethical standards.

Human and animal rights Patients signed informed consent regarding publishing their data and photographs. 
Informed consent Informed consent was obtained from all individual participants included in the study.

Open Access This article is licensed under a Creative Commons Attribution 4.0 International License, which permits use, sharing, adaptation, distribution and reproduction in any medium or format, as long as you give appropriate credit to the original author(s) and the source, provide a link to the Creative Commons licence, and indicate if changes were made. The images or other third party material in this article are included in the article's Creative Commons licence, unless indicated otherwise in a credit line to the material. If material is not included in the article's Creative Commons licence and your intended use is not permitted by statutory regulation or exceeds the permitted use, you will need to obtain permission directly from the copyright holder. To view a copy of this licence, visit http://creativecommons.org/licenses/by/4.0/.

\section{References}

1. Duke-Elder S (1964) Volume 3 Normal and abnormal development, Part 2 Congenital deformities. In: Duke-Elder S (ed) System of Ophthalmology. Henry Kimpton, London

2. Majima A (1994) Microphthalmos and its pathogenic classification [article in Japanese]. Nippon Ganka Gakkai Zasshi 98(12):1180-1200

3. Walsh MK, Goldberg MF (2007) Abnormal foveal avascular zone in nanophthalmos. Am J Ophthalmol 143(6):1067-1068. https://doi.org/10.1016/j.ajo.2007.01. 051

4. Bijlsma WR, van Schooneveld MJ, Van der Lelij A (2008) Optical coherence tomography findings for nanophthalmic eyes. Retina 28(7):1002-1007. https://doi.org/10.1097/IAE. 0b013e31816d400c

5. Xiao H, Guo X, Zhong Y, Liu X (2015) Retinal and choroidal changes of nanophthalmic eyes with and without secondary glaucoma. Retina 35(10):2121-2129. https://doi. org/10.1097/IAE.0000000000000564

6. Kaneko H, Shinojima A, Ryusaburo M, Kawamura A, Yuzawa M (2017) Choroidal thickness findings in two siblings with nanophthalmos by swept source-OCT: a case report. BMC Res Notes 10(1):16. https://doi.org/10.1186/ s13104-016-2359-x

7. Choi J, Kwon J, Shin JW, Lee J, Lee S, Kook MS (2017) Quantitative optical coherence tomography angiography of macular vascular structure and foveal avascular zone in glaucoma. PLoS ONE 12(9):e0184948. https://doi.org/10. 1371/journal.pone.0184948

8. Al-Sheikh M, Akil H, Pfau M, Sadda SR (2016) Sweptsource OCT angiography imaging of the Foveal avascular zone and macular capillary network density in diabetic retinopathy. Invest Ophthalmol Vis Sci 57(8):3907-3913. https://doi.org/10.1167/iovs.16-19570

9. Matsushita I, Nagata T, Hayashi T et al (2017) Foveal hypoplasia in patients with stickler syndrome. Ophthalmology 124(6):896-902. https://doi.org/10.1016/j.ophtha. 2017.01.046

10. Hendrickson A, Possin D, Vajzovic L, Toth CA (2012) Histologic development of the human fovea from midgestation to maturity. Am J Ophthalmol 154(5):767778.e2. https://doi.org/10.1016/j.ajo.2012.05.007

11. Maldonado RS, O'Connell RV, Sarin N et al (2011) Dynamics of human foveal development after premature birth. Ophthalmology 118(12):2315-2325. https://doi.org/ 10.1016/j.ophtha.2011.05.028

12. Leung CK, Cheng AC, Chong KK et al (2007) Optic disc measurements in myopia with optical coherence tomography and confocal scanning laser ophthalmoscopy. Invest Ophthalmol Vis Sci 48(7):3178-3183. https://doi.org/10. 1167/iovs.06-1315

13. Dubis AM, Hansen BR, Cooper RF, Beringer J, Dubra A, Carroll J (2012) Relationship between the foveal avascular zone and foveal pit morphology. Invest Ophthalmol Vis Sci 53(3):1628-1636. https://doi.org/10.1167/iovs.11-8488

14. Thomas MG, Kumar A, Mohammad S et al (2011) Structural grading of foveal hypoplasia using spectral-domain optical coherence tomography a predictor of visual acuity? Ophthalmology 118(8):1653-1660. https://doi.org/10. 1016/j.ophtha.2011.01.028

15. Villegas VM, Capó H, Cavuoto K, McKeown CA, Berrocal AM (2014) Foveal structure-function correlation in children with history of retinopathy of prematurity. Am J Ophthalmol 158(3):508-12.e2. https://doi.org/10.1016/j.ajo.2014. 05.017

16. Jonas JB, Schneider U, Naumann GO (1992) Count and density of human retinal photoreceptors. Graefes Arch Clin Exp Ophthalmol 230(6):505-510. https://doi.org/10.1007/ BF00181769

17. Hendrickson AE, Yuodelis C (1984) The morphological development of the human fovea. Ophthalmology 91(6):603-612. https://doi.org/10.1016/s01616420(84)34247-6

18. Provis JM, Dubis AM, Maddess T, Carroll J (2013) Adaptation of the central retina for high acuity vision: cones, the fovea and the avascular zone. Prog Retin Eye Res 35:63-81. https://doi.org/10.1016/j.preteyeres.2013.01.005

19. Kozulin P, Natoli R, O’Brien KM, Madigan MC, Provis JM (2009) Differential expression of anti-angiogenic factors and guidance genes in the developing macula. Mol Vis $15: 45-59$

20. Kozulin P, Natoli R, Madigan MC, O’Brien KM, Provis JM (2009) Gradients of Eph-A6 expression in primate retina suggest roles in both vascular and axon guidance. Mol Vis 15:2649-2662

21. Provis JM, Hendrickson AE (2008) The foveal avascular region of developing human retina. Arch Ophthalmol 126(4):507-511. https://doi.org/10.1001/archopht.126.4. 507

22. Yuodelis C, Hendrickson A (1986) A qualitative and quantitative analysis of the human fovea during development. Vision Res 26(6):847-855. https://doi.org/10.1016/ 0042-6989(86)90143-4

23. Xu H, Yu J, Kong X, Sun X, Jiang C (2016) Macular microvasculature alterations in patients with primary openangle glaucoma: a cross-sectional study. Medicine (Baltimore) 95(33):e4341. https://doi.org/10.1097/MD. 0000000000004341

24. Serrano JC, Hodgkins PR, Taylor DS, Gole GA, Kriss A (1998) The nanophthalmic macula. $\mathrm{Br} \mathrm{J}$ Ophthalmol 82(3):276-279. https://doi.org/10.1136/bjo.82.3.276 
25. Mohammad S, Gottlob I, Kumar A et al (2011) The functional significance of foveal abnormalities in albinism measured using spectral-domain optical coherence tomography. Ophthalmology 118(8):1645-1652. https://doi.org/ 10.1016/j.ophtha.2011.01.037

26. Spaide RF, Curcio CA (2017) Evaluation of segmentation of the superficial and deep vascular layers of the retina by optical coherence tomography angiography instruments in normal eyes. JAMA Ophthalmol 135(3):259-262. https:// doi.org/10.1001/jamaophthalmol.2016.5327

Publisher's Note Springer Nature remains neutral with regard to jurisdictional claims in published maps and institutional affiliations. 